\title{
THE EFFECT OF CONTINUOUS PASSIVE MOTION ON KNEE LIGAMENT RECONSTRUCTION WITH CARBON FIBRE
}

\author{
AN EXPERIMENTAL INVESTIGATION
}

R. ZARNETT, R. VELAZQUEZ, R. B. SALTER

From the Hospital for Sick Children, Toronto

\begin{abstract}
Our purpose was to determine whether continuous passive motion enhanced the quality of knee ligament reconstruction using carbon fibre.

In 46 rabbits the medial collateral ligaments were excised and replaced with carbon fibre prostheses. The animals were treated postoperatively by either continuous passive motion, cast immobilisation or cage activity, termed intermittent active motion.

At six weeks, the ligaments were compared histologically and biomechanically with normal (control) medial collateral ligaments and with sham-operated controls. The ligaments treated with continuous passive motion were superior to those in the other two treatment groups. There were no ligament failures in any of the groups.

This study suggests that continuous passive motion, initiated immediately postoperatively, enhances the biomechanical properties of carbon fibre ligament replacement of the medial collateral ligament while preventing the harmful effects of joint immobilisation.
\end{abstract}

Ligaments, although simple in appearance, are highly specialised structures with complex biomechanical properties (Frank et al 1983b; Claes and Neugebauer 1985). Ligaments heal by scar tissue formation (Frank et al 1983b) and the biochemical and biomechanical properties of this scar tissue are very different from those of a normal ligament. Various methods of treatment have been tried to improve the healing process including direct ligament repair, ligament augmentation, and replacement of the injured ligament by biological or synthetic materials (Salter and Bell 1981; Salter et al 1982; Frank et al 1983a, 1985; Fronek et al 1983).

The use of carbon fibre to replace ligaments was first reported by Jenkins et al (1977). It has been used experimentally and clinically as a replacement or aug-

R. Zarnett, MD, MSc, FRCS C, Orthopaedic Surgeon Humber Memorial Hospital, Toronto, Ontario, Canada.

R. Velazquez, MD, Clinical Fellow

R. B. Salter, OC, MD, FRCS C, FACS, Professor of Orthopaedic Surgery

Hospital for Sick Children, 555 University Avenue, Toronto, Ontario, Canada M5G 1 X8.

Correspondence should be sent to $\mathrm{Dr}$ R. B. Salter.

(C) 1991 British Editorial Society of Bone and Joint Surgery $0301-620 X / 91 / 1016 \$ 2.00$

J Bone Joint Surg [Br] 1991 ; 73-B:47-52. mentation for both the cruciate and the collateral ligaments of the knee (Jenkins 1978; Jenkins and McKibbin 1980; Leyshon et al 1984; King and Bulstrode 1985a,b; Neugebauer and Burri 1985; Strum and Larson 1985; Witvoet and Christel 1985).

Traditionally, injured ligaments have been treated by immobilisation during the early healing phase. The harmful effects of joint immobilisation on the articular and periarticular tissues are well known (Evan et al 1960; Salter and Field 1960; Trias 1961; Salter, McNeill and Carbin 1965; Troyer 1975). These include the formation of intra-articular adhesions, degeneration of the articular cartilage, changes in the ligament substance and weakening of ligament bony insertions (Frank et al 1984). Motion, either active or passive, has been shown to prevent these changes and to have a beneficial effect on the healing of ligaments, tendons, and articular cartilage (Salter and Ogilvie-Harris 1979; Salter et al 1980, 1982; Salter and Bell 1981; Frank et al 1984).

Carbon fibre implants are brittle (Parsons et al 1985) and the fear of early implant failure has led many surgeons to immobilise their patients' joints postoperatively for varying lengths of time. This form of treatment is based on tradition rather than on scientific evidence.

The present investigation was designed to answer the following questions: would the use of continuous passive motion (CPM), started immediately postopera- 
tively, lead to early ligament failure? Would CPM enhance the biomechanical properties of a carbon fibre ligament replacement and at the same time prevent the detrimental effects of joint immobilisation?

\section{MATERIALS AND METHODS}

A total of 46 adolescent New Zealand white rabbits each weighing 2.2 to $2.7 \mathrm{~kg}$ were used. Under general anaesthesia, induced by an intravenous injection of thiopental $(15 \mathrm{mg} / \mathrm{kg})$ and maintained by inhalation of $1 \%$ halothane, $60 \%$ nitrous oxide and $39 \%$ oxygen, one hind limb (randomly selected) was shaved from the hip to the ankle and prepared with povidine-iodine.

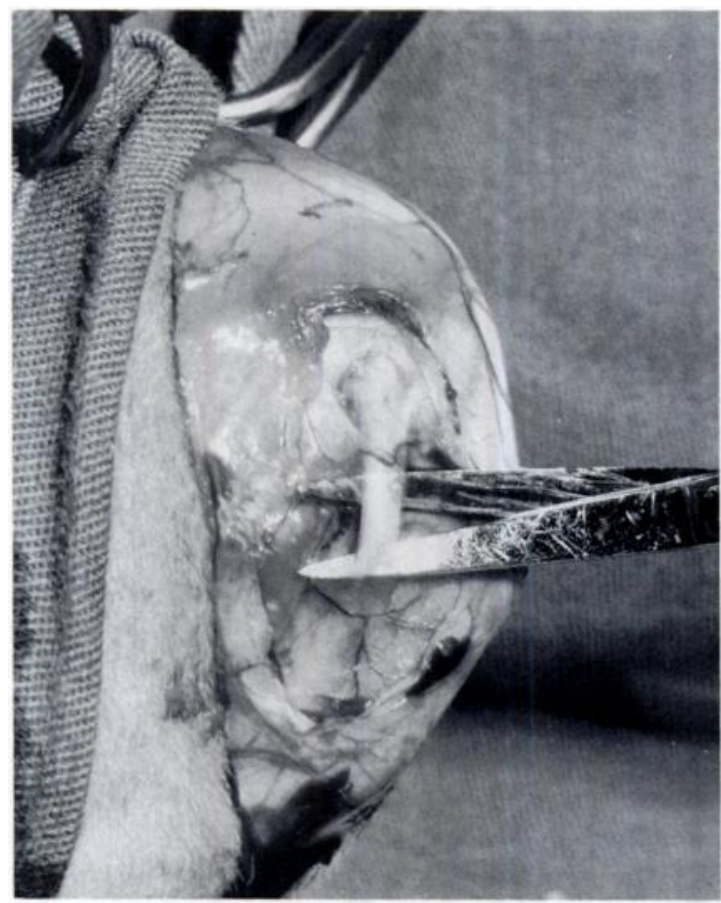

Fig. la
4-0 Vicryl suture and a subcuticular 5-0 Dexon-S suture respectively. The remaining 10 rabbits underwent an identical surgical procedure in which the MCL was excised but no carbon fibre prosthesis was inserted. These animals made up the group of sham-operated controls (SHAM).

Postoperatively, the animals receiving carbon fibre were randomly assigned to one of three groups: cast immobilisation (IMM) for three weeks, intermittent active motion or cage activity (IAM) for three weeks, or continuous passive motion (CPM) for three weeks. The SHAMS were treated in the same way as the CPM animals. After this, the animals were allowed weightbearing and freedom to run in their cages until they were

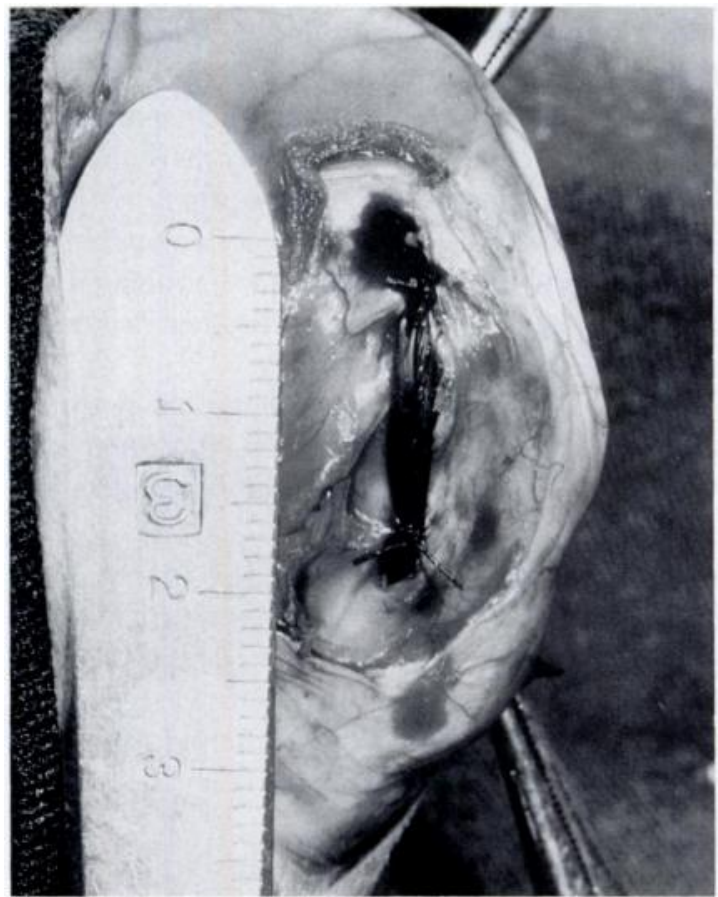

Fig. 1b

Figure la - Medial aspect of the rabbit knee. The scissors are under the isolated medial collateral ligament (MCL). Figure Ib - The MCL has been replaced by the carbon fibre implant.

The medial collateral ligament (MCL) was exposed through an anteromedial incision (Fig. 1a) and completely excised. In 36 of the animals it was replaced by an implant (Fig. 1b) consisting of carbon fibres 7 to $8 \mu \mathrm{m}$ in diameter loosely held in a 10000 fibre bundle by a glycongelatin coating (CFS, Plastafil, Victoria, Canada). The implants were passed through transverse drill holes in the proximal tibia and distal femur at sites corresponding to the origin and insertion of the MCL. The implants were then secured to the periosteum of the tibia and femur on the medial and lateral sides with 3-0 Vicryl sutures. The fascia and skin were closed with a continuous killed at six weeks. The unoperated knees in the IAM animals served as normal controls (CON).

The CPM apparatus, which has been described in detail previously (Kumar et al 1979, Salter et al 1980), moved the animal's knee through a range of motion from $40^{\circ}$ to $110^{\circ}$ at a rate of one cycle every 45 seconds. At the time of death, the range of motion in each knee was measured with a goniometer by two observers, averaged and recorded. The knees were then stripped of all soft tissues to expose the MCL.

Histology. Two knees from each group were examined histologically. This left a potential of 30 experimental 
animals (10 in each treatment group) and eight SHAM for biomechanical assessment.

One-half of each ligament was stained with haematoxylin and eosin and examined by light microscopy. The other half of each ligament was fixed and critically point dried for examination with a scanning electron microscope. Sections from the bony tunnels through which the

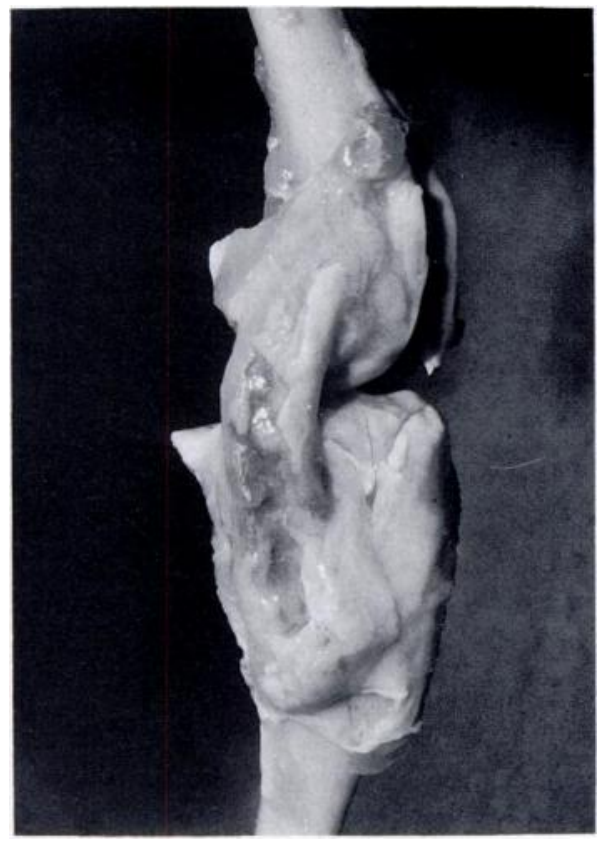

Fig. 2

Photograph of a CPM-treated MCL after six weeks. The carbon fibre implant is covered by a thick layer of fibrous tissue.

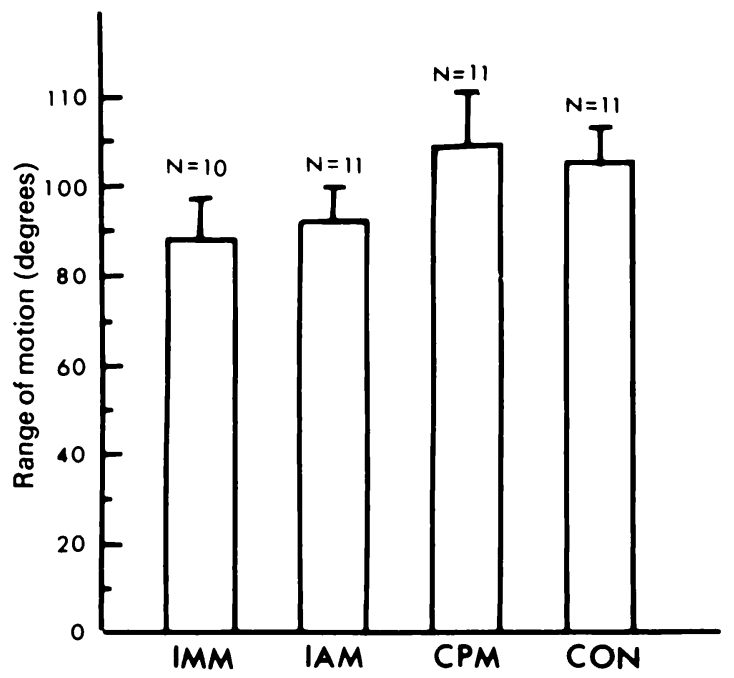

Fig. 3

Mean range of motion ( \pm SD) of the four groups of knees. The IMM and IAM groups were significantly different from the CPM group $(\mathrm{p}<0.001)$. ends of the carbon fibre bundles passed were decalcified and examined with haematoxylin and eosin.

Biomechanics. The tibia and femur were osteotomised at mid-shaft level. Transverse drill holes were made through the tibia and femur to mount the specimens on an Instron TT-CM tensile testing apparatus. All specimens were kept moist with normal saline until testing. The capsule and all the ligaments except the MCL were removed. Tensile loads were applied at a rate of $50 \mathrm{~cm} /$ minute and load deformation curves were automatically recorded on an X-Y plotter. From these curves, the force to failure (the maximum force tolerated by the specimen prior to failure), the work required to ligament failure (the area under the load deformation curve), and the ligament stiffness (the slope of the curve) were calculated. Statistical analysis was performed using a one-way analysis of variance. Where they were significant ( $p<0.05$ ), means within groups were compared using the Student-Newman-Keuls test.

\section{RESULTS}

There were no wound infections. During the postoperative period, five rabbits died of pneumonia (two from the IMM group, one from the IAM group and two from the CPM group) and one rabbit suffered a fractured femur (from the SHAM group). From the 30 experimental animals and eight SHAM animals, this left eight IMMtreated animals, nine IAM-treated animals, eight CPMtreated animals and seven SHAM-operated animals for biomechanical assessment. There were 11 unoperated control knees of the IAM-treated group (two from those used for histological assessment and nine from those used for biomechanical assessment).

Anatomy. After six weeks, all carbon fibre replacements were covered with a thick layer of fibrous tissue (Fig. 2).

There were no prosthetic failures and all knees were stable when subjected to a valgus stress. In contrast, the SHAM knees remained unstable.

There were no articular cartilage lesions or intraarticular adhesions in the CPM or the IAM animals. In three of the immobilised knees there were full thickness chondral lesions.

In three animals, carbon fibre particles were seen in the synovial membrane. In two of these, the transverse drill hole through the femur had inadvertently entered the suprapatellar pouch placing the carbon fibre in direct contact with the joint cavity.

In the SHAM group, a thin neoligament had formed in place of the excised ligament.

The mean range of motion in the CPM treated knees was equal to that in the normal knees and was significantly more ( $p<0.0001$ ) than in the other groups (Fig. 3). The immobilised knees lost an average of $14.8^{\circ}$ of motion and the cage animals $14^{\circ}$.

Biomechanics. Load deformation curves were plotted for each bone-ligament-bone complex. The site of failure 
after loading in tension was similar in the carbon fibre ligaments groups and the normal controls (Table I), generally occurring at the femoral insertion of the ligament. By contrast, six of the seven SHAM-operated ligaments failed in their mid-substance.

The load required for ligament failure was highest in the CPM group, there being no significant difference between the CPM animals and the controls (Fig. 4). The work required for ligament failure, represented by the area under the load deformation curve, was greatest in the CPM group. The ligament stiffness, represented by the slope of the load deformation curve, was highest in the control group. Comparing the four treatment groups, the CPM-treated ligaments had the greatest stiffness (Table II).

Histology. Representative sections viewed under light microscopy showed connective tissue ingrowth between the carbon fibres. This connective tissue was orientated parallel with the long axis of the individual carbon fibres.

A thick layer of fibrous tissue had formed around the periphery of the carbon fibre bundle and between its fibres (Figs 5a and b). Giant cells and histiocytes were found in association with the implants. Regardless of the method of treatment, all carbon fibre ligaments incited an intense inflammatory response.

The histological sections through the bony channels demonstrated ingrowth of immature bone and fibrous tissue into the carbon fibre ligaments. The proportion of bone to fibrous tissue was greatest in the CPM-treated animals, indicating stronger anchoring of the boneligament-bone complex (Fig. 6).

Scanning electron microscopy demonstrated that the carbon fibres were surrounded by a network of collagen. There was dense connective tissue around the periphery of the fibre bundles in addition to the connective tissue growing between the individual fibres (Fig. 7).

\section{DISCUSSION}

Immobilisation continues to be a routine part of the postoperative management of ligamentous injuries because surgeons fear that early motion will cause failure of the ligament repair or prosthesis. In the present investigation, there were no implant failures in any of the animals treated either by cage activity or by continuous passive motion.

Connective tissue grew between the carbon fibre bundles and around the entire prosthesis and the bulk of this 'neoligament' was greatest in the group treated by CPM.

In this short-term study, we did not observe any degradation of the carbon fibres and we could not therefore assess whether or not CPM had any effect on this process. The presence of giant cells and histiocytes suggests that carbon fibre elicits a foreign-body reaction, and that this occurs despite continuous passive motion.
Table I. Site of failure of ligaments after loading in tension

\begin{tabular}{llll}
\hline & \multicolumn{3}{l}{ Site of ligament failure } \\
\cline { 2 - 4 } Group* & Femur & Tibia & Mid-substance \\
\hline CPM & 7 & 0 & 1 \\
IAM & 7 & 0 & 2 \\
IMM & 6 & 1 & 1 \\
SHAM & 1 & 0 & 6 \\
CON & 10 & 0 & 0 \\
\hline
\end{tabular}

* see text

Table II. Work required for ligament failure, and ligament stiffness

\begin{tabular}{llc}
\hline Group* & $\begin{array}{l}\text { Work to failure } \\
\text { in joules } \\
\text { Mean (SD) }\end{array}$ & $\begin{array}{l}\text { Stiffness in } \\
\mathbf{c m} / \mathbf{k g} \\
\text { Mean (SD) }\end{array}$ \\
\hline CPM & $5.8(2.0)$ & $9.9(2.6)$ \\
IAM & $4.2(2.0)$ & $6.6(2.2)$ \\
IMM & $4.1(2.3)$ & $9.5(2.0)$ \\
SHAM & $2.5(0.7) \dagger$ & $3.9(1.7) \dagger$ \\
CON & $3.8(1.3)$ & $12.7(1.8) \dagger$ \\
\hline
\end{tabular}

* see text

$\dagger$ difference from CPM group significant at $\mathrm{p}<0.05$

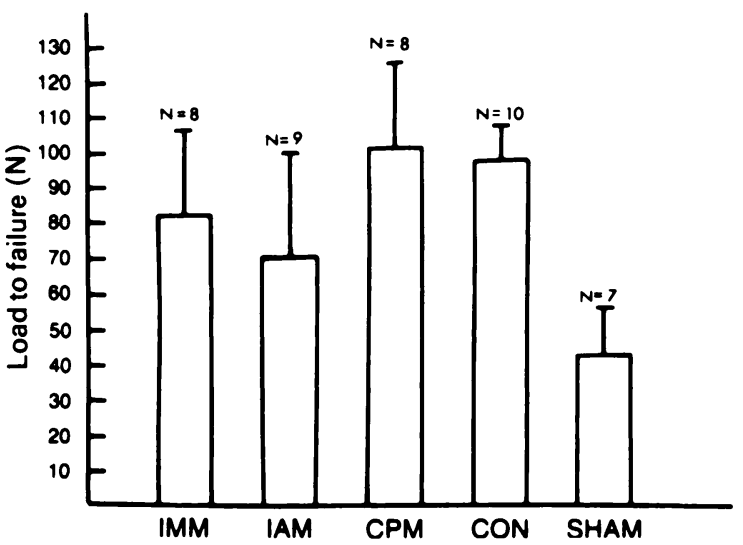

Fig. 4

Mean load in newtons $( \pm S D)$ required to rupture the ligaments in the four groups. The IAM and SHAM groups were significantly different from the CPM group $(p<0.05)$.

The toxicity of fibre particles remains to be determined. The presence of carbon particles and giant cells in the synovium of three of the animals implies that there may be problems if carbon fibre is used as an intra-articular implant (Rushton, Dandy and Naylor 1983; King and Bulstrode 1985a,b).

Six of the seven neoligaments in the SHAM-operated 


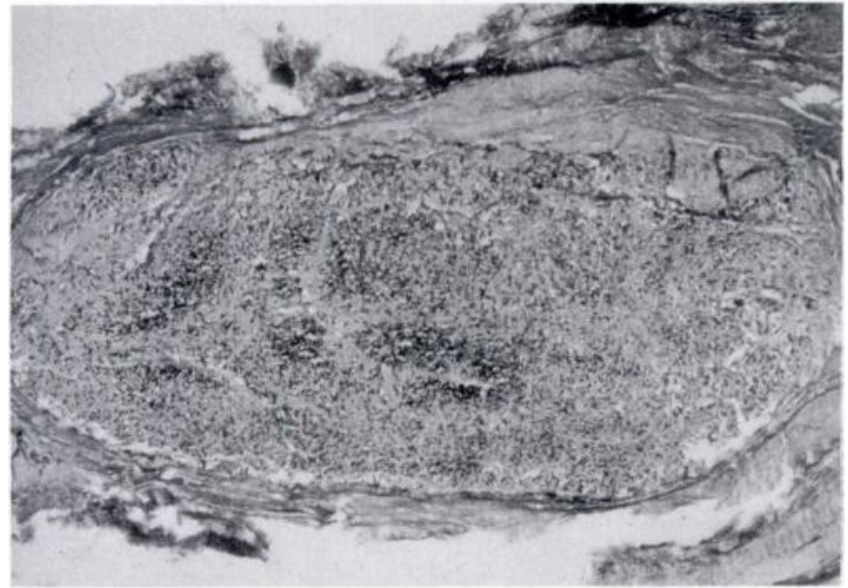

Fig. 5a

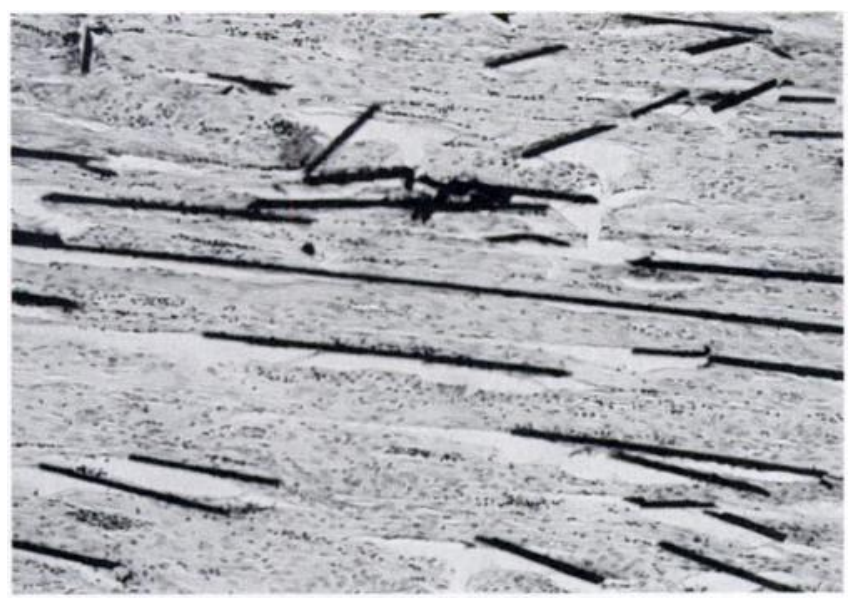

Fig. 5b

Figure 5a - Photomicrograph of a cross-section of the carbon fibre ligament at six weeks surrounded by fibrous tissue. (Trichrome; original magnification $\times 16$ ). Figure $5 b$ - Longitudinal section demonstrating collagen and connective tissue growing between the individual carbon fibres. (Haematoxylin and eosin: original magnification $\times 250$.)

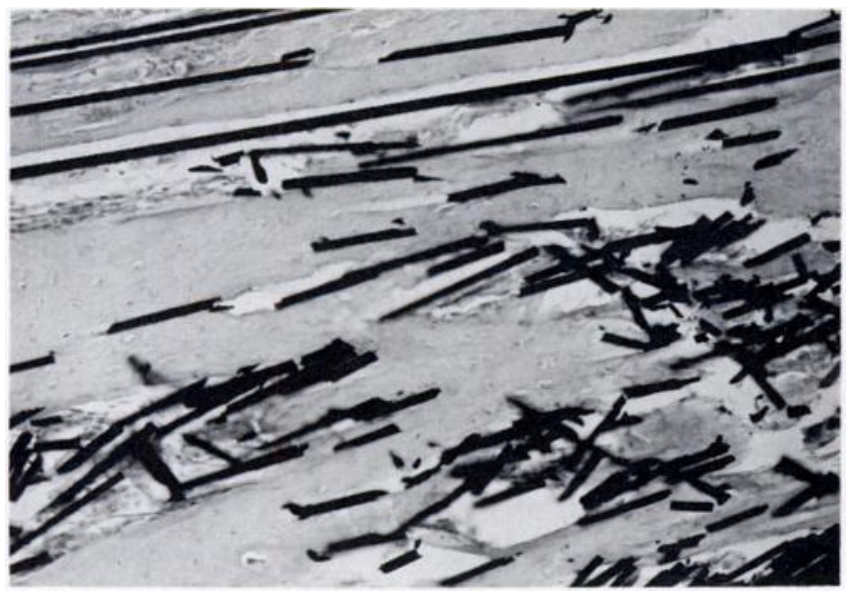

Fig. 6

Photomicrograph of the femoral insertion of a carbon fibre ligament. This specimen demonstrates the bony ingrowth in a CPM-treated animal. (Haematoxylin and eosin; original magnification $\times 250$.) group failed in their mid-substance, demonstrating that this is the weak link in the bone-ligament-bone complex. By contrast, the carbon fibre substitutions failed at their femoral insertions, as did the normal control ligaments. Claes and Neugebauer (1985) found that as time passed the strength of the connective tissue anchorage of carbon fibre to bone increased. In our series, at six weeks, the CPM-treated carbon fibre ligaments were equal in strength to the control ligaments.

The mechanism by which motion enhances ligament strength is not known. Van Royen et al (1986) studied the strength of wound healing under the influence of CPM and hypothesised that motion improves the alignment and organisation of collagen fibrils. Frank et al (1983b) postulated that CPM may have a direct effect on the cells in ligaments in addition to stimulating the formation of connective tissue (Salter et al 1980). Mendes et al (1985) suggested that the ingrowth of fibrous tissue into carbon fibre took place during limb activity and occurred when the ligament was in various degrees of tension and relaxation. Continuous passive motion would seem to be the ideal physical environment for such ingrowth to take place.

In the present investigation, the properties of the neoligaments in the immobilised groups were somewhat better than those treated by intermittent active motion. Although we have demonstrated that early passive motion is beneficial, early uncontrolled motion and early unprotected weight-bearing may not be good.

In addition to the superior biomechanical properties of the neoligaments in the CPM group, these knees maintained their normal range of motion, which was significantly greater than in any of the other groups.

Leyshon et al (1984) reviewed 63 knees which had been reconstructed with carbon fibre and treated with postoperative immobilisation. Their average loss of flexion ranged from $17^{\circ}$ to $30^{\circ}$. This loss of movement

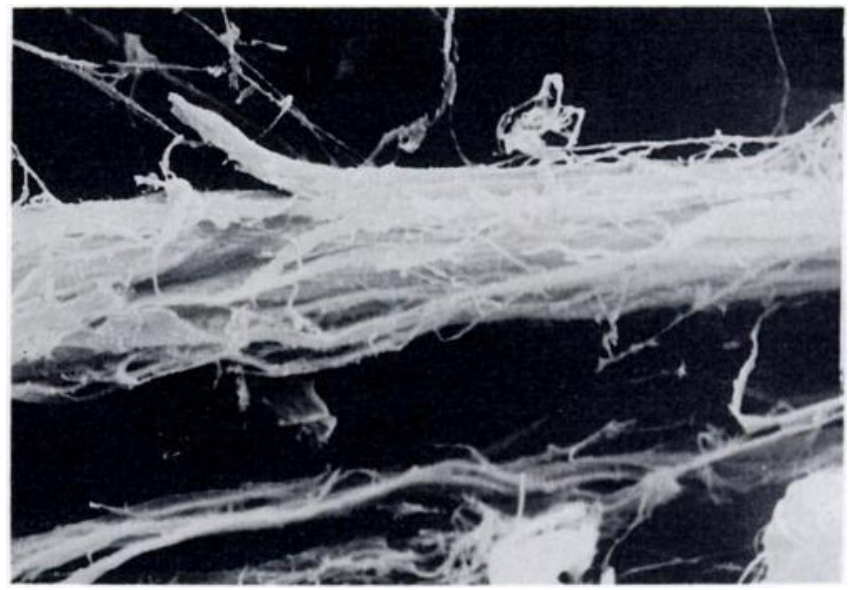

Fig. 7

Scanning electron photomicrograph, showing collagen fibrils orientated along the long axis of the carbon fibres. 
seems to be a common complication of ligament reconstructions that have been immobilised postoperatively. This complication could be avoided by the use of CPM.

Conclusion. The traditional concept that healing tissues must be rested has been challenged. CPM has been shown to have a beneficial effect on the regeneration of articular cartilage as well as upon ligament and tendon healing. In the present investigation, we have demonstrated that CPM, started immediately postoperatively, maintains a normal range of motion, protects the articular surface and enhances the biomechanical properties of carbon fibre knee ligament reconstructions.

The authors are grateful for the technical assistance of Romi Kuma and Nomi Patell. This scientific investigation has been funded by a grant from the Medical Research Council of Canada.

No benefits in any form have been received or will be received from a commercial party related directly or indirectly to the subject of this article.

\section{REFERENCES}

Claes $\mathbf{L}$, Neugebauer $\mathbf{R}$. In vivo and in vitro investigation of the longterm behavior and fatigue strength of carbon fiber ligamen replacement. Clin Orthop 1985; 196:99-111.

Evan EB, Eggers GWN, Butler JK, et al. Experimental immobilization and remobilization of rat knee joint. J Bone Joint Surg [Am] 1960 42-A :737-58.

Frank C, Schachar N, Dittrich D, et al. Electromagnetic stimulation of ligament healing in rabbits. Clin Orthop 1983a; 175:263-72.

Frank C, Woo SL-Y, Amiel D, et al. Medial collateral ligament healing: a multidisciplinary assessment in rabbits. Am J Sports Med $1983 \mathrm{~b}$ 11:379-89.

Frank C, Akeson WH, Woo SL-Y, et al. Physiology and therapeutic value of passive motion. Clin Orthop 1984; 185:113-25.

Frank C, Amiel D, Woo SL-Y, Akeson W. Normal ligament properties and ligament healing. Clin Orthop 1985; 196:15-25.

Fronek J, Frank C, Amiel D, Woo SL-Y, Coutts RD, Akeson WH. The effect of intermittent passive motion (IPM) on the healing of the medial collateral ligament. Trans 29th meeting of Orthopaedic Research Society, California, March, Vol. 8, 1983:31.

Jenkins DHR. The repair of cruciate ligaments with flexible carbon fibre: a longer term study of the induction of new ligaments and of the fate of the implanted carbon. J Bone Joint Surg [Br] 1978; 60B:520-2.

Jenkins DHR, Forster IW, McKibbin B, Ráliš ZA. Induction of tendon and ligament formation by carbon implants. J Bone Joint Surg $[\mathrm{Br}]$ 1977; 59-B:53-7.

Jenkins DHR, McKibbin B. The role of flexible carbon-fibre implants as tendon and ligament substitutes in clinical practice. J Bone Joint Surg $[\mathrm{Br}] 1980 ; 62-\mathrm{B}: 497-9$.
King JB, Bulstrode C. Polylactate-coated carbon fiber in extra-articular reconstruction of the unstable knee. Clin Orthop 1985a; 196: $139-42$

King JB, Bulstrode CJK. Extra-articular carbon fibre at the knee. $J$ Bone Joint Surg [Br] 1985b; 67-B:156-7.

Kumar A, Wong DA, Johnson RG, et al. The restraint of rabbits in a special sling. Lab Anim Sci 1979; 29:512-5.

Leyshon RL, Channon GM, Jenkins DHR, Ráliš ZA. Flexible carbon fibre in late ligamentous reconstruction for instability of the knee. $J$ Bone Joint Surg [Br] 1984; 66-B: 196-200.

Mendes DG, Lusim M, Angel D, et al. Histologic pattern of biomechanic properties of the carbon fiber-augmented ligament tendon. Clin Orthop 1985; 196:51-60.

Neugebauer R, Burri C. Carbon fiber ligament replacement in chronic knee instability. Clin Orthop 1985; 196:118-23.

Parsons JR, Bhayani S, Alexander $\mathrm{H}$, Weiss AB. Carbon fiber debris within the synovial joint: a time-dependent mechanical and histologic study. Clin Orthop 1985; 196:69-76.

Rushton N, Dandy DJ, Naylor CPE. The clinical arthroscopic and histological findings after replacement of the anterior cruciate ligament with carbon-fibre. J Bone Joint Surg [Br] 1983; 65-B : 308-9.

Salter RB, Field P. The effects of continuous compression on living articular cartilage: an experimental investigation. $J$ Bone Joint Surg $[\mathrm{Am}] 1960 ; 42-\mathrm{A}: 31-49$.

Salter RB, McNeill OR, Carbin R. The pathological changes in articular cartilage with persistent joint injury: an experimental investigation. In: Studies of rheumatoid disease Procs 3rd Canadian conference: research in rheumatic diseases, Toronto, 1965: University of Toronto Press, 1966:33-47.

Salter RB, Ogilvie-Harris DJ. Healing of intra-articular fractures with continuous passive motion. AAOS Instructional Course Lectures. St. Louis: CV Mosby Co, 1979:28:102-17.

Salter RB, Simmonds DF, Malcolm BW, Rumble EJ, Macmichael D, Clements ND. The biological effect of continuous passive motion on the healing of full-thickness defects in articular cartilage: an experimental investigation in the rabbit. J Bone Joint Surg [Am] $1980 ; 62-A: 1232-51$

Salter RB, Bell RS. The effect of continuous passive motion on the healing of partial thickness lacerations of the patellar tendon of the rabbit. Orthop Tran 1981; 5:209.

Salter RB, Minster RR, Clements N, et al. Continuous passive motion and the repair of full-thickness articular cartilage defects - $a$ one year follow up. Orthop Tran 1982; 2:266.

Strum GM, Larson RL. Clinical experience and early results of carbon fiber augmentation of anterior reconstruction of the knee. Clin Orthop 1985; 196:124-38.

Trias A. Effect of persistent pressure on the articular cartilage. $J$ Bone Joint Surg [Br] $1961 ;$ 43-B:376-86.

Troyer $\mathbf{H}$. The effect of short-term immobilization on the rabbit knee joint cartilage: a histochemical study. Clin Orthop 1975; 107: 249-57.

van Royen BJ, O'Driscoll SW, Dhert WJA, Salter RB. A comparison of the effects of immobilization and continuous passive motion on surgical wound healing in mature rabbits. Plast Reconstr Surg $1986 ; 78: 360-6$.

Witvoet J, Christel P. Treatment of chronic anterior knee instabilities with combined intra- and extra-articular transfer augmented with carbon-PLA fibers. Clin Orthop 1985; 196:143-53. 